\title{
Managing pregnancy in inflammatory rheumatological diseases
}

\author{
Varsha Jain ${ }^{1}$ and Caroline Gordon*1,2
}

\begin{abstract}
Historically, pregnancy in women with many inflammatory rheumatic diseases was not considered safe and was discouraged. Combined care allows these pregnancies to be managed optimally, with the majority of outcomes being favorable. Disease activity at the time of conception and anti-phospholipid antibodies are responsible for most complications. Disease flares, pre-eclampsia, and thrombosis are the main maternal complications, whereas fetal loss and intrauterine growth restriction are the main fetal complications. Antirheumatic drugs used during pregnancy and lactation to control disease activity are corticosteroids, hydroxychloroquine, sulphasalzine, and azathioprine. Vaginal delivery is possible in most circumstances, with cesarean section being reserved for complications.
\end{abstract}

\section{Introduction}

Autoimmune rheumatic disease covers a spectrum of conditions, including systemic lupus erythematosus (SLE), antiphospholipid syndrome (APS), rheumatoid arthritis (RA), other inflammatory arthropathies/spondyloarthropathies, systemic sclerosis (SSc), and systemic vasculitides. Historically, pregnancy was not deemed safe in women with multisystem rheumatic diseases, either because of the risk of that their condition would deteriorate or because of their medications. As this review will show, this view has changed and current opinion is that with good disease control, careful planning, and combined management, delivery of healthy babies is often possible. Family size is smaller in women with rheumatic diseases because of a combination of factors, including

\footnotetext{
${ }^{*}$ Correspondence: p.c.gordon@bham.ac.uk

${ }^{2}$ Rheumatology Research Group, School of Immunity and Infection, College of Medical and Dental Sciences, University of Birmingham, Vincent Drive, Birmingham, UK

Full list of author information is available at the end of the article
}

disease activity, drug exposure, psychosocial factors, and self-exclusion $[1,2]$.

\section{Fertility}

Inflammatory rheumatological diseases affect women of childbearing age, and fertility is an important consideration. Fertility is not usually affected by the rheumatic diseases; however, factors that impact on female fertility include cytotoxic drugs, amenorrhoea accompanying severe flares, and renal insufficiency [3].

The main cytotoxic drug that poses a threat to fertility is cyclophosphamide. It is known to cause premature ovarian failure, and the risk is dependent on the age at which it is started, the duration of treatment, and the cumulative dose. Boumpas and colleagues [4] showed that none of the women who were under the age of 25 years and who had not more than 7 pulses of intravenous cyclophosphamide developed sustained amenorrhoea. However, all the women who were over 30 years and who received at least 15 intravenous pulses of cyclophosphamide developed sustained amenorhoea [4]. The risk varies with the regime used, and another study of 84 patients with SLE showed that two thirds of cases had successful pregnancies $[5,6]$.

Elizur and colleagues [7] suggested that fertility preservation should be offered to all women with severe renal/ extrarenal manifestations of SLE or other systemic rheumatic diseases requiring cyclophosphamide at doses that might preclude them from having their own biological child. Options available include ovulation induction therapy, oocyte or embryo cryopreservation, or in vivo maturation of oocytes. Ovulation induction therapy may promote flares in patients with lupus and precipitate thromboembolism in women with antiphospholipid antibodies [8].

\section{Effects of the rheumatological disease and pregnancy on the mother}

Systemic lupus erythematosus

\section{Disease activity}

There is much debate in the literature as to whether lupus activity increases during pregnancy. Studies have involved varied cohorts of patients and controls, making 
the studies difficult to compare. The hormonal changes that occur in pregnancy seem to be responsible for inducing lupus activity, and it appears that $40 \%$ to $50 \%$ of patients have a measurable increase in disease activity. The risk of a severe flare is lower and is estimated at 15\% to $30 \%$. Flares are typically cutaneous, arthritic, or hematological. The risk of flare is increased if there is evidence of a flare within 6 months prior to conception, active lupus nephritis, very active lupus in the past, and/ or discontinuation of medication [9-11]. There is a risk of flares in the postpartum period even if disease has been in remission before and during pregnancy. Diagnosis of lupus flare is important to distinguish from pregnancyrelated physiological changes or complications. These features are outlined in Table 1 [12].

\section{Pregnancy effects}

Women with SLE are at an increased risk of developing medical complications during pregnancy, regardless of whether their lupus is active or not [13]. Owing to hormonal changes, the risk of thrombosis is increased two to three times during pregnancy and the first 6 weeks after delivery. There is a $5 \%$ to $10 \%$ risk that a pregnant woman with SLE will develop a thrombosis during this period, even in the absence of APS [14].

Women with SLE are at higher risk of maternal complications (disease flares, pregnancy-induced hypertension $[\mathrm{PIH}]$, pre-eclampsia, eclampsia, diabetes, or thrombosis) and fetal complications (recurrent fetal loss, growth restriction, or fetal distress in labor) [13]. As a result, they tend to have longer hospital stays and a higher rate of cesarean section. Maternal mortality, though rare, is increased approximately 20 times compared with that of women in general in the US $[13,15]$.

Pre-eclampsia is defined as PIH in association with proteinuria (greater than $0.3 \mathrm{~g}$ in 24 hours) and edema, but virtually any organ may be affected. This is a common pregnancy-related complication in SLE. About 25\% of women with SLE develop pre-eclampsia, and the risk is higher for women with pre-existing hypertension, a history of lupus nephritis, or anti-phospholipid antibodies $[13,15]$. Differentiating between active lupus nephritis and pre-eclampsia is crucial, and it is important to note that the two can coexist. The presence of hypertension with recent-onset proteinuria makes preeclampsia more likely than lupus nephritis, as hypertension is very rarely an early sign of active renal disease. Red or white cells in the urine in the presence of proteinuria are more likely to be due to lupus nephritis (after excluding infection, bleeding, or calculi). Urinary casts are the best marker for active renal lupus. Blood tests that help to distinguish active renal disease from pre-eclampsia include an increase in anti-doublestranded DNA (anti-dsDNA) titres or a $25 \%$ decrease in
Table 1. Features that help to distinguish systemic lupus erythematosus disease activity from pregnancy-induced changes

\begin{tabular}{ll}
\hline Unreliable features & Reliable features \\
\hline Facial/palmar erythema & Palpable lupus rash \\
Arthralgia & Synovitis \\
Anemia & Alopecia (localized) \\
Low platelets & Leucopenia (new, not drug-related) \\
Hypertension & Red cells or casts (or both) in urine \\
Proteinuria & $\begin{array}{l}\text { Rising anti-dsDNA (anti-double-stranded DNA) } \\
\text { antibodies }\end{array}$ \\
Low C4 with normal C3 & $\begin{array}{l}\text { 25\% decrease in C3 and C4 (may be in normal } \\
\text { range) }\end{array}$ \\
Classical pathway activation & Alternative pathway activation \\
\hline
\end{tabular}

complement levels (C3 and $\mathrm{C} 4)$ (even within the normal range) or both [12].

\section{Antiphospholipid syndrome \\ 1. Disease activity}

APS is characterized by the presence of anti-phospholipid antibodies and either vascular thrombosis or pregnancy morbidity [16]. Primary APS occurs in isolation in $50 \%$ of patients, whereas secondary APS can be associated with any other autoimmune disease, most commonly SLE. The increased risk of thrombosis during all pregnancies is increased further in patients with APS and most often presents as deep vein thrombosis, pulmonary emboli, stroke, hepatic infarction, recurrent miscarriages, and premature delivery for fetal distress or pre-eclampsia. Anti-phospholipid antibodies may also initiate an inflammatory process involving the activation of complement that affects placental function and results in poor pregnancy outcomes [17]. Patients with lupus anticoagulant and/or previous pulmonary emboli are at risk of pulmonary hypertension that may deteriorate in pregnancy which is associated with a $50 \%$ risk of maternal mortality $[18,19]$.

\section{Pregnancy effects}

The presence of anti-phospholipid antibodies predisposes the patient to PIH, pre-eclampsia, and eclampsia, the last of which usually presents as one or more convulsions superimposed on pre-eclampsia. Pre-eclampsia may occur in patients with APS pregnancy earlier than in healthy women, from 22 weeks [20]. HELLP syndrome is a thrombotic microangiopathic disorder consisting of hemolysis, elevated liver enzymes, and low platelets. It presents typically in the third trimester but in patients with APS may present with pre-eclampsia earlier than in healthy women, even as early at 15 weeks of gestation [21-24]. 
Rheumatoid arthritis and other inflammatory arthropathies/spondyloarthropathies

\section{Disease activity}

In $\mathrm{RA}$, provided that disease activity is stable at the time of conception, approximately $75 \%$ of patients notice an improvement in their condition within the first trimester and approximately a quarter go into remission [25]. The risk of flares is increased in the postpartum period, and the majority of women have flares within the first 3 months after delivery but only about $40 \%$ are of moderate severity $[25,26]$. The immunological basis for these changes remains uncertain but is thought to involve changes in regulatory $T$ cells, monocytes, and galactosylation levels of immunoglobulin G [27-31].

Pregnancy generally improves physical functioning in patients with RA but not in those with ankylosing spondylitis. Emotional and mental health during pregnancy are unaffected in both conditions [32]. Women with spondyloarthropathy generally notice an improvement in their peripheral arthritis and uveitis during pregnancy [33]; however, spinal disease tends to remain unchanged or worsen. Postpartum flares are common in the first 3 months following delivery and are unrelated to disease activity during pregnancy, duration of lactation, or time of return of menses [14].

\section{Pregnancy effects}

Pregnancy outcomes for women with RA and spondyloarthropathies tend to be favorable; however, these women have increased lengths of hospital stay, increased rate of premature rupture of membranes, and higher cesarean section delivery rates in comparison with healthy women [15]. There is no increased risk of pre-eclampsia in RA [34].

\section{Systemic sclerosis}

\section{Disease effects}

Scleroderma, the skin changes of SSc, tends not to change in pregnancy. Raynaud phenomenon usually improves because of the physiological increase in cardiac output. Gastroesophageal reflux disease is seen to worsen but is a common presentation in all pregnant women. Recurrent vomiting can cause Mallory-Weiss tears in the esophagus already thinned by disease-related fibrosis; therefore, prompt management is of importance in the prevention of life-threatening bleeding [35]. One of the most serious complications that occurs in pregnant women with SSc is renal crisis due to acute-onset severe hypertension. A daily increase in serum creatinine and lack of proteinuria in the early stages support a diagnosis of renal crisis due to SSc. Renal crisis is most common in patients with early diffuse SSc (within 5 years of symptom onset), anti-tropoisomerase and anti-RNA polymerase III antibodies, and exposure to high-dose corticosteroids
[35]. Pulmonary hypertension is another serious complication and is associated with 50\% maternal mortality, and most vigilance is required 48 to 72 hours after delivery. Screening should be done before pregnancy, and termination should be offered if the complication is diagnosed in pregnancy [36].

\section{Pregnancy effects}

Women with SSc have a higher rate of hypertensive disease, including pre-eclampsia, and have an increased length of hospital stay compared with normal women [15]. Elevated liver function tests and proteinuria with edema are more common in pre-eclampsia and HELLP syndrome than in SSc renal crisis. Hypertension or renal dysfunction due to pre-eclampsia, but not due to active SSc, will be resolved by delivery [12].

\section{Vasculitides}

\section{Disease effects}

There are very few prospective studies of vasculitides in pregnancy. Vasculitides can occur at any age but are generally more frequent in men and in women beyond their reproductive period [37]. Planning conception at a time of disease inactivity usually allows women with Wegener granulomatosis (WG), polyarteritis nodosa (PAN), or Churg-Strauss syndrome to remain well during pregnancy. They are at risk of deterioration during pregnancy and the first 6 weeks after delivery should conception occur when the disease is inadequately treated or newly active $[38,39]$.

Only 38 cases of WG have been reported in the literature: 21 were in remission at conception, 13 were diagnosed during pregnancy, and 4 had active disease at the time of conception. Flares have a bimodal distribution, most commonly occurring either in the first or second trimester or in the month after delivery. Maternal death has been reported twice, once following therapeutic abortion and once 1 month after delivery [38,40,41].

There are eight reports of pregnancy and PAN $[12,39,42]$. Conceiving at a time when PAN is active puts the mother at higher risk of death; hence, therapeutic abortion is recommended in the early phase of pregnancy, or high-dose corticosteroids with cyclophosphamide are recommended in the late stages [39].

In Churg-Strauss syndrome, respiratory and cardiac systems are most commonly affected during relapse. Asthma is more common but cardiac involvement can lead to irreversible myocardial damage requiring heart transplantation, so careful pre-pregnancy screening and management of pregnancy are critical $[39,43]$.

In Takayasu arteritis (TA), severe aortic valvular disease and aortic aneurysm are risk factors for maternal morbidity and fatality; therefore, pregnancy is discouraged in these patients [39]. Less frequently, heart 
failure, renal insufficiency, and cerebral hemorrhage have been reported. Despite these complications, the outcome of pregnancy is generally favorable provided that there is little delay in seeking medical advice [44].

Behçet disease (BD) improves during pregnancy in most patients; however, exacerbations occurred in about a sixth of patients in a case control study [45]. BD is associated with an increased risk of thrombosis and vascular involvement, including central venous thrombosis [46].

\section{Pregnancy effects}

Hypertensive disease is more common in women with WG and renal involvement than in normal pregnant women. It is the presenting feature in TA and pregnancy, and pre-eclampsia complicated $62 \%$ of cases in a recent single-center Indian study [47]. Pregnancy complications and cesarean section were significantly higher in $\mathrm{BD}$ patients than in controls [45], as with most other vasculitides, particularly TA and WG. Like lupus nephritis, renal vasculitis needs to be distinguished from pre-eclampsia; however, blood tests (c-ANCA [antineutrophil cytoplasmic antibody and classical cytoplasmic staining complete heart block] and anti-PR3 [antiproteinase-3]) are helpful only in diagnosing renal vasculitis due to WG.

\section{Effects of the autoimmune disease on the fetus Fetal loss}

'Fetal loss' incorporates spontaneous abortion from less than than 10 weeks, miscarriages from 10 to 19 weeks, and stillbirths from 20 weeks of gestation. The most important factors in predicting fetal loss in SLE, APS, SSc, and vasculitis are previous fetal loss, disease activity at conception (especially renal), maternal hypertension, and the presence of anti-phospholipid antibodies [12,48]. Fetal loss is not increased in those with inflammatory arthropathies or spondyloarthropathies in the absence of maternal complications.

\section{Intrauterine growth restriction}

The risk of intrauterine growth restriction (IUGR) in SLE and APS pregnancies is about three times that in controls [15]. The risk of IUGR is increased in those with active disease at conception and in those with anti-phospholipid antibodies $[9,11,16]$. IUGR increases the risk of premature delivery and is thought to occur due to uteroplacental dysfunction secondary to thrombosis and complement activation; however, the exact mechanisms are unknown [17].

\section{Premature delivery}

Premature delivery, which is defined as occurring before 38 weeks of gestation, is common in lupus, APS, SSc, and the vasculitides $[12,13,35,44,49]$. Pre-term delivery is not associated with RA [34]. The most important complication of premature delivery is respiratory distress syndrome. In this condition, the newborn can suffer from respiratory distress due to insufficient surfactant. If premature delivery is imminent, the mother should be given a course of corticosteroids to promote fetal lung development at least 24 hours before birth. The current UK guidelines recommend two doses of betamethesome $12 \mathrm{mg}$ intramuscularly (12 hours apart) or four doses of dexamethasone $6 \mathrm{mg}$ (12 hours apart) [50].

\section{Neonatal lupus}

Neonatal lupus is a model of passive autoimmunity in mothers who carry anti-Ro (SSA) or anti-La (SSB) antibodies or both. Antibodies cross the placenta from about week 16 and are associated with (a) irreversible congenital complete heart block (CHB) in the fetus or (b) transient photosensitive rash on the face or scalp or various liver and hematological abnormalities or neurological manifestations in the newborn or (c) both. CHB is defined as atrioventicular block diagnosed in utero, at birth, or within the neonatal period ( 0 to 27 days after birth) and is present in approximately $1 \%$ to $2 \%$ of women with anti-Ro/La antibodies [51-53]. CHB is permanent, and although most children do well with pacemakers, the cumulative probability of survival at 3 years of age was only $80 \%$ in one report [52]. Neonatal lupus rash is present in $10 \%$ to $20 \%$, and laboratory abnormalities (anemia, thrombocytopenia, neutropenia, and abnormal liver function tests) were detected in up to $27 \%$ of babies in a prospective study [51]. The risk of recurrence of $\mathrm{CHB}$ is about $20 \%$ in a subsequent pregnancy after an affected child [53].

Women who are at risk of having a baby with $\mathrm{CHB}$ are recommended to have regular monitoring [54], but guidelines vary among countries and among units. In the UK, the midwife should listen to fetal heart rate on a weekly basis to identify bradycardia from week 16 onwards and the baby should have heart rate confirmed while being scanned monthly. Formal fetal echocardiography occurs at the 20-week anomaly scan, and further echocardiograms are done if an abnormality is suspected. Partial heart block can be identified on fetal electrocardiogram [54]. Intravenous immunoglobulin (IVIG) has been reported to successfully treat severe thrombocytopenia associated with neonatal lupus [55], but IVIG does not prevent recurrence of CHB [56]. All babies born to mothers with anti-Ro/La should have an electrocardiogram after birth to look for first- and second-degree heart block as they may progress to third-degree later.

\section{Neonatal autoimmune thrombocytopenia}

Transmission of anti-platelet antibodies across the placenta in women with APS is recognized to cause 
thrombocytopenia in infants. Occasionally, this presents as intracranial hemorrhage [57]. Thrombocytopenia usually resolves within 6 months as the mother's antibodies are cleared from the circulation. IVIG may be used as treatment for severe thrombocytopenia [58].

\section{Pre-pregnancy considerations}

To avoid or reduce the complications discussed above, pre-pregnancy planning and screening must be carefully undertaken. Combined care involving rheumatologists, nephrologists, hematologists, or other relevant physicians, obstetricians, and anesthetists is preferred for all but simple inflammatory arthropathies. Management of the pregnant patient with inflammatory rheumatological disease should be tailored to the individual's disease activity and history. Pregnancy during disease remission provides the best results as described above, and patients should be advised not to get pregnant until the disease has been well controlled for 6 months on non-teratogenic drugs that can be continued in pregnancy to reduce the risk of flares. A review of all medication that might affect pregnancy should be undertaken.

Side effects of teratogenic medication, such as methotrexate, cyclophosphamide, mycophenolate mofetil, or leflunomide, must be discussed prior to commencing treatment, and information on contraceptive methods should be offered with advice on when the drugs and contraception should be stopped prior to pregnancy (Table 2). Most contraceptive choices, including emergency contraceptive choices, can be offered to patients with rheumatological diseases, but there is a potential risk of thrombosis in APS if the patient is not fully anticoagulated. Estrogen-containing contraceptives can be used with care in patients with mild non-active lupus but, owing to the increased risk of thrombosis, should be avoided in women with anti-phospholipid antibodies or APS [59-61].

Disease activity should be assessed by standard criteria for each disease and potential risk factors for pregnancy complications - including anti-Ro/-La and anti-phospholipid antibodies (including IgG and IgM anticardiolipin and $\beta 2$ glycoprotein-I antibodies and lupus anticoagulant), hypertension, and diabetes and raised serum creatinine, 24-hour proteinuria, or protein/ creatinine ratio - should be identified [12,48]. Echocardiography and lung function tests should be done if there have been cardiac, lung, or thrombotic complications, particularly if there is a risk of pulmonary hypertension $[18,19,36]$.

As with other women planning pregnancy, a healthy diet and appropriate exercise are recommended and smoking, using illicit drugs, or drinking alcohol are discouraged. Folic acid $(0.4 \mathrm{mg})$ should be started 3 months prior to pregnancy and continued until
12 weeks of gestation to prevent neural tube defects [62]. Women taking folate antagonists such as sulphasalazine are usually advised to take $5 \mathrm{mg}$ daily throughout pregnancy and lactation.

\section{Management of pregnancy Drugs}

A summary of drugs available for use in patients with inflammatory rheumatological conditions in pregnancy is provided in Table 2. Specific attention should be given to the most commonly used drugs: analgesia, corticosteroids, sulphasalazine, azathioprine, hydroxychloroquine, aspirin, and heparin and those that are contraindicated [49,63-66].

Paracetamol is the first-line analgesic. Mild opioids such as codeine or pethidine are preferred if needed, as they can be easily reversed. The concerns are that the newborn may present with respiratory depression or opioid dependency or both [67]. Tramadol has embryotoxic effects in animals and should be avoided.

Corticosteroids can be divided into non-fluorinated steroids (prednisolone and methyprednisolone) and fluorinated steroids (betamethasone and dexamethasone) [64]. Approximately $90 \%$ of prednisolone is metabolized by the enzyme 11- $\beta$-hydroxysteroid dehydrogenase in the placenta; as a result, about $10 \%$ reaches the fetus. It is widely used, therefore, to treat maternal disease or flares (or both) in pregnancy. Fluorinated steroids are not metabolized by the placenta and reach the fetus in their active form. These steroids are used to treat or prevent fetal complications, but reversal of $\mathrm{CHB}$ has not been achieved $[54,64,68]$. All steroids increase the maternal risk of hypertension, pre-eclampsia, premature rupture of membranes, infection, and diabetes, so the lowest effective dose must be used (ideally not more than $15 \mathrm{mg} /$ day).

Sulphasalazine has been used for many years for arthropathies and inflammatory bowel disease in pregnancy. Hydroxychloroquine is an anti-malarial used mainly in the treatment of SLE and reduces the risk of maternal disease flare and possibly thrombosis and does not cause fetal damage. Women are recommended to continue with hydroxychloroquine throughout pregnancy and lactation $[14,69]$. Azathioprine is a cytotoxic immunosuppressant used mainly in SLE and vasculitis. The fetus lacks the enzyme inosinatopyrophophorylase, which is required to convert azathioprine to its active metabolite 6-mercaptopurine, and therefore azathioprine is safe to use in pregnancy. Azathioprine can be used to control severe maternal disease, and doses of not more than $2 \mathrm{mg} /$ $\mathrm{kg}$ per day are associated with few side effects [64].

\section{Treatment and prevention of flares}

Provided that conception occurs during remission, the risk of flares is low. The patient's condition should be kept 
Table 2. Commonly used drugs in inflammatory rheumatological diseases, their fetal effects, and recommendations during pregnancy

\begin{tabular}{llll}
\hline Class & Drug & Fetal effects & Recommendation \\
\hline Analgesic & Paracetamol & Not known to be harmful & Can be used during pregnancy \\
Analgesic (high dose) & Aspirin & Low dose (antithrombotic dose) 75 mg daily is safe and & Can be continued throughout \\
and antiplatelet agent & & lowers risk of premature delivery and pre-eclampsia.
\end{tabular}

Anti-inflammatory NSAIDs

(analgesic) drugs

$\begin{array}{ll}\text { Analgesic } & \text { Codeine } \\ \text { Analgesic } & \text { Pethidine } \\ \text { Analgesic } & \text { Tramadol } \\ \text { Analgesic } & \text { Morphine } \\ \text { Anti-inflammatory } & \begin{array}{l}\text { Cyclo-oxygenase } \\ \text { (analgesic) agent }\end{array} \\ \begin{array}{l}\text { inhibitors } \\ \text { (COX inhibitors) } \\ \text { agents }\end{array} & \text { Corticosteroids }\end{array}$

Disease-modifying

agent

Disease-modifying agent

Disease-modifying
agent
Disease-modifying
agent
Disease-modifying
agent
Disease-modifying
agent

Azathioprine

Ciclosporin

Cyclophosphamide

Methotrexate

Disease-modifying agent

Disease-modifying agent

Disease-modifying agent

Biological agent

Hydroxycholoquine

Leflunomide

Mycophenolate mofetil

Gold salts lowers risk of premature delivery and pre-eclampsia. At higher doses (analgesic doses), there is potential risk of impaired renal function, pulmonary hypertension, or clotting ability in newborn.

If given within 14 days of delivery, premature closure of ductus arteriosus, which can lead to pulmonary hypertension. Possible risk of cardiac septal defects and gastroschisis

Respiratory depression and withdrawal symptoms in neonate if opioid used during delivery

Respiratory depression and withdrawal symptoms in neonate if opioid used during delivery

Embryotoxicity in animals

Respiratory depression and withdrawal symptoms in neonate if opioid used during delivery

Impaired renal function, decreased fetal urine output, development of oligohydramnios. Teratogenic in animal studies.

Prolonged treatment $>15 \mathrm{mg} /$ day increases risk of premature rupture of membranes and preterm labor. Increased risk of oral cleft and palate at high doses.

No associated congenital abnormalities or malformations

Folic acid antagonist. Associated with two- to threefold increased risk of oral clefts and cardiovascular anomalies. Risk diminished by concomitant use of folic acid throughout pregnancy.

Small risk of depressed hematopoiesis in infant in doses of $>2 \mathrm{mg} / \mathrm{kg}$ per day

No increase in rate of birth defects but risk of maternal hypertension and intrauterine growth restriction

Embryopathy with growth defects, developmental delay, craniofacial defects, or distal limb defects

Increased risk of congenital abnormalities in central nervous system, cranial ossification, limbs, palate, and growth retardation.

Inhibits de novo synthesis of pyramidine in activated lymphocytes, leads to increased risk of embryotoxicity and teratogenicity in animals.

Tumor necrosis factoralpha inhibitors (for example, infliximab, Recently identified phenotype of craniofacial malformations affecting oral cavity and ears as well as ocular anomalies. Less frequently, limb abnormalities, with congenital cardiovascular, renal, or central nervous system malformations.

Cross placenta, found in fetal liver and kidneys, no evidence of increase in neonatal malformations in small number of reports available

No toxic effects in animals, sporadic adverse events in humans but insufficient to determine toxicity or safety
Discontinue at 32 weeks of gestation, earlier if premature delivery suspected. Need 2-week gap between stopping NSAIDs and delivery. If needs to be used, ibuprofen preferred to diclofenac as shorter half-life.

Use at lowest effective dose, but avoid during labor.

Can be used during pregnancy

Avoid during pregnancy

Avoid during pregnancy

Should be avoided

Can be continued in pregnancy but should be lowest effective dose. (See 'Drugs' subsection of 'Management of pregnancy'section.)

Can be continued throughout pregnancy

Can be continued in pregnancy but requires folic acid supplementation throughout pregnancy

Can be continued in pregnancy, not more than $2 \mathrm{mg} / \mathrm{kg}$ per day

Can be continued in pregnancy up to dose of $2.5 \mathrm{mg} / \mathrm{kg}$ per day

Discontinue at least 3 months prior to conception. Effective contraception vital during this time.

Discontinue 3 months prior to conception. Wait at least one menstrual cycle after stopping drug before trying to conceive.

Stop 2 years before conception or use washout procedure with cholestyramine.

Discontinue and switch to azathioprine at least 3 months prior to conception.

May be continued

Discontinue at missed period or positive pregnancy test. 
Table 2. Continued

\begin{tabular}{|c|c|c|c|}
\hline Class & Drug & Fetal effects & Recommendation \\
\hline Biological agent & Abatacept & Crosses placenta in animals, no data in human pregnancies & $\begin{array}{l}\text { Discontinue at least } 10 \text { weeks prior to } \\
\text { conception. }\end{array}$ \\
\hline Biological agent & Anakinra & No evidence with human pregnancy & Discontinue use prior to conception. \\
\hline Biological agent & Rituximab & $\begin{array}{l}\text { Actively transported across placenta, with neonatal levels } \\
\text { being higher than maternal levels. Can lead to transient B-cell } \\
\text { depletion in neonate, no infections reported. }\end{array}$ & $\begin{array}{l}\text { Discontinue } 1 \text { year prior to } \\
\text { conception. }\end{array}$ \\
\hline $\begin{array}{l}\text { Prevention or } \\
\text { treatment of } \\
\text { osteoporosis }\end{array}$ & Bisphosphonates & $\begin{array}{l}\text { Cross placenta and accumulate in fetal bone, causing bone } \\
\text { abnormalities in animals. }\end{array}$ & $\begin{array}{l}\text { Discontinue } 2 \text { years before planned } \\
\text { pregnancy as retained in human } \\
\text { skeleton and released in circulation for } \\
\text { at least } 2 \text { years after stopping drug. }\end{array}$ \\
\hline $\begin{array}{l}\text { Prevention or } \\
\text { treatment of } \\
\text { osteomalacia and } \\
\text { osteoporosis }\end{array}$ & $\begin{array}{l}\text { Calcium and } \\
\text { vitamin D } \\
\text { supplements }\end{array}$ & Therapeutic doses unlikely to be harmful & Can be continued in pregnancy \\
\hline $\begin{array}{l}\mathrm{H} 2 \text { blocker to } \\
\text { reduce gastric } \\
\text { acid production }\end{array}$ & Ranitidine & Not known to be harmful & $\begin{array}{l}\text { Can be continued in pregnancy } \\
\text { (extensive experience) }\end{array}$ \\
\hline $\begin{array}{l}\text { Proton pump } \\
\text { inhibitors }\end{array}$ & $\begin{array}{l}\text { Omeprazole } \\
\text { (lansoprazole) }\end{array}$ & Not known to be harmful & May be continued (less experience) \\
\hline $\begin{array}{l}\text { Anti-hypertensive } \\
\text { agent }\end{array}$ & $\begin{array}{l}\text { Angiotensin- } \\
\text { converting enzyme } \\
\text { inhibitors }\end{array}$ & $\begin{array}{l}\text { Adversely affect fetal and neonatal blood pressure control } \\
\text { and renal function. Skull defects and oligohydramnios have } \\
\text { been reported. }\end{array}$ & $\begin{array}{l}\text { Discontinue } 3 \text { months prior to } \\
\text { conception. Contraindicated in } \\
\text { pregnancy except possibly in } \\
\text { scleroderma renal crisis. }\end{array}$ \\
\hline $\begin{array}{l}\text { Anti-hypertensive } \\
\text { agent and vasodilator }\end{array}$ & $\begin{array}{l}\text { Calcium channel } \\
\text { blockers }\end{array}$ & No significant abnormalities & $\begin{array}{l}\text { Can be continued in pregnancy (more } \\
\text { experience with nifedipine than } \\
\text { amlodipine or others) }\end{array}$ \\
\hline Anticoagulant & Heparin & $\begin{array}{l}\text { Does not cross placenta and is not associated with } \\
\text { congenital defects. }\end{array}$ & $\begin{array}{l}\text { Can be continued in pregnancy, but } \\
\text { owing to heparin-induced osteopenia, } \\
\text { calcium and vitamin D supplements } \\
\text { are needed }\end{array}$ \\
\hline Anticoagulant & Warfarin & Risk of fetal warfarin syndrome & $\begin{array}{l}\text { Contraindicated in first and third } \\
\text { trimesters of pregnancy but can be } \\
\text { used in postpartum period }\end{array}$ \\
\hline
\end{tabular}

NSAID, non-steroidal anti-inflammatory drug.

stable on medication that can be continued throughout pregnancy, such as prednisolone, hydroxychloroquine, sulphasalazine, and azathioprine. If these drugs are stopped, there is an increased risk of flare $[14,69,70]$.

Mild flares of lupus, vasculitis, or arthritis are usually treated with low-dose prednisolone (less than $15 \mathrm{mg}$ per day). Higher doses or intravenous pulse methylprednisolone is used for severe flares. Non-teratogenic medication such as azathioprine, ciclosporin, or tacrolimus may be used. Cyclophosphamide and mycophenolate mofetil are occasionally used when all other options have been exhausted in the third trimester [11,38,39].

\section{Management of recurrent pregnancy losses}

Managing recurrent fetal losses depends on understanding the mechanism(s) underlying fetal loss. Three specific causes have been identified: disease activity (which is controlled as discussed above), maternal complications such as pre-eclampsia, or thrombosis. Thrombosis is most commonly associated with anti-phospholipid antibodies, and treatment occurs in one of two ways. The first is the use of antiplatelet/anticoagulant therapy, mainly aspirin and heparin. In the literature, there is much debate about the correct regime, and optimal doses have not been agreed upon. The current recommended guideline for women who have recurrent miscarriages is combination therapy of low-dose aspirin with lowmolecular-weight heparin [64,71,72]. A randomized, controlled trial found no difference between giving aspirin only versus giving aspirin and heparin [73]. However, in that trial (as in a number of studies), not all patients had confirmed APS according to the Sydney criteria, making results difficult to interpret [16].

\section{Treatment and prevention of hypertension\{}

Non-teratogenic anti-hypertensives should be taken before and during pregnancy. Labetalol, nifedipine, methyldopa, and hydralazine are used to control hypertension. Angiotensin-converting enzyme inhibitors and angiotensin receptor blockers are contraindicated because 


\begin{tabular}{|c|c|}
\hline Disease & Complications that may affect use of analgesia and anesthesia \\
\hline Systemic lupus erythematosus & $\begin{array}{l}\text { Pericarditis or valvular abnormalities } \\
\text { Pulmonary hypertension, pleural effusions, or lupus pneumonitis } \\
\text { Peripheral neuropathies, central nervous system dysfunction (seizures), or psychological problems } \\
\text { Hematological abnormalities (anemia, thrombocytopenia, or coagulopathy) } \\
\text { Lupus nephritis }\end{array}$ \\
\hline Antiphospholipid syndrome & $\begin{array}{l}\text { Coexisting autoimmune disease, secondary organ involvement, and thrombotic phenomena, including pulmonary } \\
\text { hypertension } \\
\text { Anticoagulation }\end{array}$ \\
\hline Rheumatoid arthritis & $\begin{array}{l}\text { Cervical spine involvement (exclude atlantoaxial anterior subluxation and avoid excessive manipulation of neck during } \\
\text { general anesthesia) } \\
\text { Hip disease that might prevent vaginal delivery } \\
\text { Pleural/pericardial effusions and pulmonary parenchymal involvement }\end{array}$ \\
\hline Ankylosing spondylitis & $\begin{array}{l}\text { Assess presence of extra-articular (cardiopulmonary) features and use of opiate analgesics } \\
\text { Temporo-mandibular joint dysfunction, cervical and lumbar spine (for general, epidural, or spinal anesthesia), and hip } \\
\text { involvement (for vaginal delivery) }\end{array}$ \\
\hline Systemic sclerosis & $\begin{array}{l}\text { Renal disease, systemic hypertension, pulmonary hypertension, or cardiac dysfunction } \\
\text { Assess peripheral pulses, peripheral venous access, extent of Raynaud phenomenon, and skin involvement }\end{array}$ \\
\hline Vasculitis & $\begin{array}{l}\text { Organ ischemia (cardiac, renal, cerebral, and limb) and intravascular volume } \\
\text { Monitor hypertension and end organ complications or thrombosis }\end{array}$ \\
\hline
\end{tabular}

of teratogenicity. They are the mainstay of treatment in renal crisis of SSc and may be used after appropriate discussion with the mother if hypertension is lifethreatening [36]. Aspirin may reduce pre-eclampsia and prematurity. Many centers use it in high-risk pregnancies, including lupus and other systemic autoimmune diseases, to reduce the risk of pre-eclampsia and thrombosis $[74,75]$. If pre-eclampsia is severe or progresses to eclampsia, delivery is the definitive treatment.

\section{Treatment of esophageal reflux and dyspepsia}

Dyspepsia is a common symptom in pregnant women and can be worsened by aspirin, non-steroidal antiinflammatory drugs, and corticosteroids. Antacids such as gaviscon are rarely sufficient. Ranitidine, a histamine2-antagonist, is used at doses of between 150 and $600 \mathrm{mg}$ daily, especially in patients with SSc $[76,77]$. There is less experience with proton pump inhibitors such as omeprazople, but they are probably safe in pregnancy $[76,78]$.

\section{Delivery}

Women with chronic disease generally want to have a 'natural' delivery like healthy women. With effective prepregnancy planning and joint care, vaginal delivery should be possible; cesarean delivery is reserved for obstetric emergencies, those with a history of cesarean section who do not want a trial of vaginal delivery, and women with severe hip disease. However, to reduce the risk of stillbirth in patients with APS or active disease, induction may be advisable at 38 to 39 weeks. Detailed plans for delivery should be made by a multi-disciplinary team that includes the obstetrician, anesthetist, and relevant physicians at 36 weeks of gestation or earlier in
Table 4. Benefits of breastfeeding

\begin{tabular}{ll}
\hline Reduced risk in child & Reduced risk in mother \\
\hline Infections & Type 2 diabetes \\
Atopic dermatitis & Breast cancer \\
Asthma (young children) & Ovarian cancer \\
Obesity & Postpartum depression (if not stopped early) \\
Type 1 and 2 diabetes & \\
Childhood leukemia & \\
Sudden infant death syndrome & \\
Necrotising enterocolitis
\end{tabular}

patients with complications. Owing to the risk of placental insufficiency in SLE, APS, SSc, and vasculitis, babies need to be monitored by growth scans every 4 weeks throughout pregnancy and closely monitored during delivery for any signs of fetal distress. Disease-specific considerations for anesthesia are listed in Table 3.

Epidural can be offered for routine vaginal deliveries. For cesarean section, neuroaxial anesthetic can be performed; general anesthetic is reserved for obstetric emergencies (for example, placental abruption, uterine rupture, prolapsed umbilical cord, or fetal distress). The last dose of heparin should be given 12 hours before the epidural will be administered, and the first dose after delivery should be 12 hours later. Aspirin may be given up until the time of delivery and is compatible with spinal and epidural anesthesia, although practice still varies among centers [79].

\section{Breastfeeding}

Breastfeeding has multiple health benefits for both the mother and child (Table 4) [80]. Table 5 summarizes 
Table 5. Commonly used anti-rheumatic drugs and their use during breastfeeding

\begin{tabular}{|c|c|c|}
\hline Drug & Crosses into breast milk & Compatible with lactation \\
\hline Paracetamol & Amount too small to be harmful & Can be continued during breastfeeding \\
\hline Aspirin & $\begin{array}{l}\text { Possible risk of Reye syndrome } \\
\text { In large doses, could impair platelet function }\end{array}$ & $\begin{array}{l}\text { Low doses (antithrombotic dose of } 75 \text { mg/day) acceptable, } \\
\text { but avoid in large doses }\end{array}$ \\
\hline NSAIDs & $\begin{array}{l}\text { Very small quantities in human breast milk } \\
\text { Potential risk of jaundice and kernicterus }\end{array}$ & $\begin{array}{l}\text { Approved for use (use short-acting NSAIDs such as } \\
\text { ibuprofen) }\end{array}$ \\
\hline Codeine & $\begin{array}{l}\text { Amount usually too small to be harmful; however, } \\
\text { mothers vary in capacity to catabolize codeine and infant } \\
\text { at risk of morphine overdose }\end{array}$ & Use lowest effective dose if needed, but try to avoid \\
\hline Pethidine & Present in breast milk but not known to be harmful & Can be used \\
\hline Tramadol & Amount probably too small to be harmful & Should be avoided \\
\hline Morphine & $\begin{array}{l}\text { Therapeutic doses unlikely to affect infant } \\
\text { Withdrawal symptoms in infants of dependent mothers }\end{array}$ & Therapeutic doses may be used if needed, but try to avoid \\
\hline Corticosteroids & $\begin{array}{l}\text { Trace amounts of hydrocortisone and up to } 25 \% \text { of } \\
\text { maternal levels of prednisolone detectable in breast milk }\end{array}$ & $\begin{array}{l}\text { Breastfeed } 4 \text { hours after last dose to minimize exposure if } \\
\text { prednisolone of greater than } 20 \mathrm{mg}\end{array}$ \\
\hline $\begin{array}{l}\text { COX-2 (cyclo-oxygenase-2) } \\
\text { inhibitors }\end{array}$ & Insufficient data in humans & Avoid due to theoretical risk \\
\hline Hydroxychloroquine & Found in breast milk but no abnormalities reported & Can be continued during breastfeeding \\
\hline Methotrexate & Excreted in low concentrations into breast milk & Contraindicated \\
\hline Leflunomide & No published data available & Contraindicated due to theoretical risk \\
\hline Sulfasalazine & Negligible amounts secreted in breast milk & To be used with folic acid supplements \\
\hline Gold salts & $\begin{array}{l}\text { Excreted in breast milk and absorbed by infant } \\
\text { Can lead to rash, nephritis, hepatitis, and hematological } \\
\text { problems }\end{array}$ & Should be avoided \\
\hline Azathioprine & $\begin{array}{l}\text { Azathioprine and its metabolites detected in breast milk } \\
\text { in low amounts, but abnormalities rare }\end{array}$ & $\begin{array}{l}\text { May be used at not more than } 2 \mathrm{mg} / \mathrm{kg} \text { per day after } \\
\text { discussion with mother weighing up risk-benefit }\end{array}$ \\
\hline Cyclosporin & Wide variability in drug disposition & $\begin{array}{l}\text { May be used after discussion with mother weighing up } \\
\text { risk-benefit, preferably at doses lower than } 2.5 \mathrm{mg} / \mathrm{kg} \text { per day }\end{array}$ \\
\hline Cyclophosphamide & Excreted in breast milk & Contraindicated \\
\hline Mycophenolate mofetil & No human studies & Contraindicated due to theoretical risk \\
\hline $\begin{array}{l}\text { Tumor necrosis factor-alpha } \\
\text { antagonists (for example, } \\
\text { infliximab, etanercept, and } \\
\text { adalimumab) }\end{array}$ & $\begin{array}{l}\text { Etanercept excreted in breast milk } \\
\text { Infliximab undetectable } \\
\text { No studies with adalimumab }\end{array}$ & Not enough data, therefore should be avoided \\
\hline Anakinra & Unknown whether excreted in breast milk & Not enough data, therefore should be avoided \\
\hline Abatacept & $\begin{array}{l}\text { Not known whether excreted in breast milk or whether } \\
\text { absorbed systematically after ingestion }\end{array}$ & Contraindicated due to theoretical risk \\
\hline Rituximab & Unknown whether excreted in breast milk & Not enough data, therefore should be avoided \\
\hline $\begin{array}{l}\text { Intravenous immunoglobulin } \\
\text { weighing up risk-benefit }\end{array}$ & No published data & May be used during breastfeeding after discussion \\
\hline $\begin{array}{l}\text { Heparin and low-molecular- } \\
\text { weight heparin }\end{array}$ & Not excreted in breast milk & Can be continued during breastfeeding \\
\hline Warfarin & Minimal excretion in breast milk & Can be used while breastfeeding \\
\hline
\end{tabular}

NSAID, non-steroidal anti-inflammatory drug.

recommendations for treatment during lactation [49,63-66]. It is widely agreed that prednisolone, sulphasalazine, and hydroxychloroquine are acceptable $[64,69$, 81]. Azathioprine use during lactation remains more controversial $[64,81]$ but has been used by us and others without obvious harm to the infant, as levels of the active metabolites are rare in breast milk and undetectable in the baby $[64,82,83]$.

\section{Conclusions}

With careful planning, most women with inflammatory rheumatological diseases can have successful pregnancies (Table 6). It is important that conception occur when the disease has been inactive for at least 6 months and while the mother is taking non-teratogenic drugs. The mother and fetus require regular monitoring throughout pregnancy so that any complications can be detected 


\section{Table 6. Key points in the management of patients with rheumatological diseases in pregnancy}

With thorough pre-pregnancy planning, most pregnancies in women with inflammatory rheumatic diseases are low-risk and have a favorable outcome. Fertility is generally not affected by autoimmune rheumatic disease.

Systemic lupus erythematosus is the most widely studied rheumatic disease in pregnancy, and it is important to differentiate active lupus disease from pathophysiological changes of pregnancy.

Antiphospholipid syndrome is secondary to another autoimmune disease in $50 \%$ of cases. Anti-phospholipid antibodies are associated with an increased risk of thrombosis, fetal loss, pre-eclampsia, intrauterine growth restriction, and premature labor.

Rheumatoid arthritis and Behçet disease usually improve during pregnancy but are still associated with a risk of flare in the postpartum period.

Disease at the time of conception is the most important factor in determining maternal and fetal outcome.

HELLP (hemolysis, elevated liver enzymes, and low platelets) and pre-eclampsia occur in women with autoimmune rheumatic disease (especially, antiphospholipid syndrome) earlier than in healthy women and must be distinguished from disease activity and treated appropriately.

Neonatal lupus is specific to mother with anti-Ro/La antibodies and can lead to irreversible congenital complete heart block, requiring a permanent pacemaker in affected children.

Drug therapy must be reviewed prior to conception and during pregnancy and breastfeeding in order to rule out any potential harmful side effects to the fetus/child.

Vaginal delivery is generally deemed safe. Cesarean sections are reserved for patients with obstetric complications.

early and managed appropriately. Combined care involving obstetricians, rheumatologists, other relevant physicians, and anesthetists will promote the best outcomes for mother and baby.

\section{Abbreviations}

APS, antiphospholipid syndrome; BD, Behçet disease; $\mathrm{CHB}$, complete heart block; HELLP, hemolysis, elevated liver enzymes, and low platelets; IUGR, intrauterine growth restriction; IVIG, intravenous immunoglobulin; PAN, polyarteritis nodosa; $\mathrm{PIH}$, pregnancy-induced hypertension; RA, rheumatoid arthritis; SLE, systemic lupus erythematosus; SSc, systemic sclerosis; TA,

Takayasu arteritis; WG, Wegener granulomatosis.

\section{Competing interests}

The authors declare that they have no competing interests.

\section{Author details}

${ }^{1}$ Rheumatology Department, City Hospital, Sandwell and West Birmingham Hospitals NHS Trust, Dudley Road, Birmingham, B18 7QH, UK; ${ }^{2}$ Rheumatology Research Group, School of Immunity and Infection, College of Medical and Dental Sciences, University of Birmingham, Vincent Drive, Birmingham, UK.

\section{Published: 25 February 2011}

\section{References}

1. Vinet E, Pineau C, Gordon C, Clarke AE, Bernatsky S: Systemic lupus erythematosus in women: impact on family size. Arthritis Rheum 2008, 59:1656-1660.

2. Ekblom-Kullberg $\mathrm{S}$, Kautiainen $\mathrm{H}$, Alha $\mathrm{P}$, Helve T, Leirisalo-Repo M, Julkunen $H$ : Reproductive health in women with systemic lupus erythematosus compared to population controls. Scand J Rheumatol 2009, 38:375-380.

3. Costa M, Colia D: Treating infertility in autoimmune patients. Rheumatology (Oxford) 2008, 47 Suppl 3:iii38-iii41.

4. Boumpas DT, Austin HA, III, Vaughan EM, Yarboro CH, Klippel JH, Balow JE: Risk for sustained amenorrhea in patients with systemic lupus erythematosus receiving intermittent pulse cyclophosphamide therapy. Ann Intern Med 1993, 119:366-369.

5. Huong DL, Amoura Z, Duhaut P, Sbai A, Costedoat N, Wechsler B, Piette JC Risk of ovarian failure and fertility after intravenous cyclophosphamide. A study in 84 patients. J Rheumato/ 2002, 29:2571-2576.

6. Appenzeller S, Blatyta PF, Costallat LT: Ovarian failure in SLE patients using pulse cyclophosphamide: comparison of different regimes. Rheumatol Int 2008, 28:567-571.

7. Elizur SE, Chian RC, Pineau CA, Son WY, Holzer HE, Huang JY, Gidoni Y, Levin D, Demirtas $E$, Tan SL: Fertility preservation treatment for young women with autoimmune diseases facing treatment with gonadotoxic agents. Rheumatology (Oxford) 2008, 47:1506-1509.
8. Huong DL, Wechsler B, Vauthier-Brouzes D, Duhaut P, Costedoat N, Lefebvre $G$, Piette JC: Importance of planning ovulation induction therapy in systemic lupus erythematosus and antiphospholipid syndrome: a single center retrospective study of 21 cases and 114 cycles. Semin Arthritis Rheum 2002, 32:174-188.

9. Surita FG, Parpinelli MA, Yonehara E, Krupa F, Cecatti JG: Systemic lupus erythematosus and pregnancy: clinical evolution, maternal and perinatal outcomes and placental findings. Sao Paulo Med J 2007, 125:91-95.

10. Phadungkiatwattana $P$, Sirivatanapa $P$, Tongsong T: Outcomes of pregnancies complicated by systemic lupus erythematosus (SLE). J Med Assoc Thai 2007, 90:1981-1985

11. Clowse ME: Lupus activity in pregnancy. Rheum Dis Clin North Am 2007 33:237-252, v.

12. Gordon C: Pregnancy and autoimmune diseases. Best Pract Res Clin Rheumatol 2004, 18:359-379.

13. Clowse ME, Jamison M, Myers $E_{\text {, James }} \mathrm{AH}$ : A national study of the complications of lupus in pregnancy. Am J Obstet Gynecol 2008, 199:127. e1-6.

14. Mitchell K, Kaul M, Clowse ME: The management of rheumatic diseases in pregnancy. Scand J Rheumatol 2010, 39:99-108.

15. Chakravarty EF, Nelson L, Krishnan E: Obstetric hospitalizations in the United States for women with systemic lupus erythematosus and rheumatoid arthritis. Arthritis Rheum 2006, 54:899-907.

16. Rand JH: The antiphospholipid syndrome. Hematology Am Soc Hematol EduC Program 2007, 136-142.

17. Abrahams VM: Mechanisms of antiphospholipid antibody-associated pregnancy complications. Thromb Res 2009, 124:521-525.

18. McMillan E, Martin WL, Waugh J, Rushton I, Lewis M, Clutton-BrockT, Townend JN, Kilby MD, Gordon C: Management of pregnancy in women with pulmonary hypertension secondary to SLE and anti-phospholipid syndrome. Lupus 2002, 11:392-398.

19. Prabu A, Patel K, Yee CS, Nightingale P, Situnayake RD, Thickett DR, Townend $\mathrm{JN}$, Gordon C: Prevalence and risk factors for pulmonary arterial hypertension in patients with lupus. Rheumatology (Oxford) 2009, 48:1506-1511

20. Yamada H, Atsumi T, Kobashi G, Ota C, Kato EH, Tsuruga N, Ohta K, Yasuda S, Koike T, Minakami H: Antiphospholipid antibodies increase the risk of pregnancy-induced hypertension and adverse pregnancy outcomes. J Reprod Immunol 2009, 79:188-195.

21. Le Thi Thuong D, Tieulié N, Costedoat N, Andreu MR, Wechsler B, VauthierBrouzes D, Aumaître O, Piette JC: The HELLP syndrome in the antiphospholipid syndrome: retrospective study of 16 cases in 15 women. Ann Rheum Dis 2005, 64:273-278.

22. Tsirigotis P, Mantzios G, Pappa V, Girkas K, Salamalekis G, Koutras A, Giannopoulou V, Spirou K, Balanika A, Papageorgiou S, Travlou A, Dervenoulas $\mathrm{J}$ : Antiphospholipid syndrome: a predisposing factor for early onset HELLP syndrome. Rheumatol Int 2007, 28:171-174. 
23. Bornstein E, Barnhard $Y$, Atkin R, Divon MY: HELLP syndrome: a rare, early presentation at 17 weeks of gestation. Obstet Gynecol 2007, 110:525-527.

24. Marnach M, VanWinter J, Watson W: Myocarditis: an unusual cause of postpartum fever in pregnancy complicated by antiphospholipid syndrome. Am J Perinatol 2007, 24:405-408.

25. de Man YA, Dolhain RJ, van de Geijn FE, Willemsen SP, Hazes JM: Disease activity of rheumatoid arthritis during pregnancy: results from a nationwide prospective study. Arthritis Rheum 2008, 59:1241-1248.

26. Keeling SO, Oswald AE: Pregnancy and rheumatic disease: 'by the book' or 'by the doc'. Clin Rheumato/ 2009, 28:1-9.

27. Ostensen M, Villiger PM: The remission of rheumatoid arthritis during pregnancy. Semin Immunopathol 2007, 29:185-191.

28. Forger F, Marcoli N, Gadola S, Moller B, Villiger PM, Ostensen M: Pregnancy induces numerical and functional changes of $C D 4+C D 25$ high regulatory T cells in patients with rheumatoid arthritis. Ann Rheum Dis 2008 67:984-990.

29. Haupl T, Ostensen M, Grutzkau A, Radbruch A, Burmester GR, Villiger PM: Reactivation of rheumatoid arthritis after pregnancy: increased phagocyte and recurring lymphocyte gene activity. Arthritis Rheum 2008, 58:2981-2992.

30. Haupl T, Ostensen M, Grutzkau A, Burmester GR, Villiger PM: Interaction between rheumatoid arthritis and pregnancy: correlation of molecular data with clinical disease activity measures. Rheumatology (Oxford) 2008, 47 Suppl 3:iii19-iii22.

31. Forger F, Ostensen M: Is IgG galactosylation the relevant factor for pregnancy-induced remission of rheumatoid arthritis? Arthritis Res Ther 2010, 12:108.

32. Forger F, Ostensen M, Schumacher A, Villiger PM: Impact of pregnancy on health related quality of life evaluated prospectively in pregnant women with rheumatic diseases by the SF-36 health survey. Ann Rheum Dis 2005, 64:1494-1499.

33. Gran JT, Ostensen M: Spondyloarthritides in females. Baillieres Clin Rheumatol 1998, 12:695-715.

34. Nelson JL, Ostensen M: Pregnancy and rheumatoid arthritis. Rheum Dis Clin North Am 1997, 23:195-212

35. Miniati I, Guiducci S, Mecacci F, Mello G, Matucci-Cerinic M: Pregnancy in systemic sclerosis. Rheumatology (Oxford) 2008, 47 Suppl 3:iii16-iii18.

36. Steen VD: Pregnancy in scleroderma. Rheum Dis Clin North Am 2007 33:345-358, vii.

37. Harper L, Savage CO: ANCA-associated renal vasculitis at the end of the twentieth century--a disease of older patients. Rheumatology (Oxford) 2005, 44:495-501.

38. Koukoura O, Mantas N, Linardakis H, Hajiioannou J, Sifakis S: Successful term pregnancy in a patient with Wegener's granulomatosis: case report and literature review. Fertil Steril 2008, 89:457.e1-5

39. Doria A, Bajocchi G, Tonon M, Salvarani C: Pre-pregnancy counselling of patients with vasculitis. Rheumatology (Oxford) 2008, 47 Suppl 3:iii13-iii15.

40. Kim SY, Linton JM, Kolasinski SL: Successful treatment of new onset Wegener's granulomatosis with IVIG (intravenous immunoglobulin) during pregnancy: a case report. Mod Rheumato/ 2008, 18:177-180.

41. Alfhaily $F$, Watts $R$, Leather A: Wegener's granulomatosis occurring de novo during pregnancy. Clin Exp Rheumatol 2009, 27 (1 Suppl 52):S86-S88.

42. Owada K, Katoh T, Asano K, Watanabe K, Shigetomi S, Watanabe T: Successful pregnancy complicated by microscopic polyarteritis nodosa. Clin Nephrol 2005, 63:500-502.

43. Corradi D, Maestri R, Facchetti F: Postpartum Churg-Strauss syndrome with severe cardiac involvement: description of a case and review of the literature. Clin Rheumatol 2009, 28:739-743.

44. Sharma BK, Jain S, Vasishta K: Outcome of pregnancy in Takayasu arteritis. Int J Cardiol 2000, 75 Suppl 1:S159-S162.

45. Jadaon J, Shushan A, Ezra Y, Sela HY, Ozcan C, Rojansky N: Behcet's disease and pregnancy. Acta Obstet Gynecol Scand 2005, 84:939-944.

46. Kale A, Akyildiz L, Akdeniz N, Kale E: Pregnancy complicated by superior vena cava thrombosis and pulmonary embolism in a patient with Behcet disease and the use of heparin for treatment. Saudi Med J 2006, 27:95-97.

47. Suri V, Aggarwal N, Keepanasseril A, Chopra S, Vijayvergiya R, Jain S: Pregnancy and Takayasu arteritis: a single centre experience from North India. J Obstet Gynaecol Res 2010, 36:519-524.

48. Saar P, Hermann W, Muller-Ladner U: Connective tissue diseases and pregnancy. Rheumatology (Oxford) 2006, 45 Suppl 3:iii30-iii32.

49. Levy RA, Jesus GR, Jesus NR: Obstetric antiphospholipid syndrome: still a challenge. Lupus 2010, 19:457-459

50. Crane J, Armson A, Brunner M, De La Ronde S, Farine D, Keenan-Lindsay L, Leduc L, Schneider C, Van Aerde J; Executive Committee of the Society of Obstetricians and Gynaecologists of Canada: Antenatal corticosteroid therapy for fetal maturation. J Obstet Gynaecol Can 2003, 25:45-52.

51. Cimaz R, Spence DL, Hornberger L, Silverman ED: Incidence and spectrum of neonatal lupus erythematosus: a prospective study of infants born to mothers with anti-Ro autoantibodies. J Pediatr 2003, 142:678-683.

52. Friedman DM, Rupel A, Buyon JP: Epidemiology, etiology, detection, and treatment of autoantibody-associated congenital heart block in neonatal lupus. Curr Rheumatol Rep 2007, 9:101-108.

53. Brucato A, Cimaz R, Caporali R, Ramoni V, Buyon J: Pregnancy outcomes in patients with autoimmune diseases and anti-Ro/SSA antibodies. Clin Rev Allergy Immunol 2011, 40:27-41.

54. Buyon JP, Clancy RM, Friedman DM: Cardiac manifestations of neonatal lupus erythematosus: guidelines to management, integrating clues from the bench and bedside. Nat Clin Pract Rheumatol 2009, 5:139-148.

55. Chunharas A, Nuntnarumit $P$, Hongeng S, Chaunsumrit A: Neonatal lupus erythematosus: clinical manifestations and management. J Med Assoc Thai 2002, 85 Suppl 4:S1302-S1308.

56. Pisoni CN, Brucato A, Ruffatti A, Espinosa G, Cervera R, Belmonte-Serrano M, Sánchez-Román J, García-Hernández FG, Tincani A, Bertero MT, Doria A, Hughes GR, Khamashta MA: Failure of intravenous immunoglobulin to prevent congenital heart block: findings of a multicenter, prospective, observational study. Arthritis Rheum 2010, 62:1147-1152.

57. Chou AK, Hsieh SC, Su YN, Jeng SF, Chen CY, Chou HC, Tsao PN, Hsieh WS: Neonatal and pregnancy outcome in primary antiphospholipid syndrome: a 10-year experience in one medical center. Pediatr Neonatol 2009, 50:143-146.

58. Branch DW, Porter TF, Paidas MJ, Belfort MA, Gonik B: Obstetric uses of intravenous immunoglobulin: successes, failures, and promises. J Allergy Clin Immunol 2001, 108 (4 Suppl):S133-S138.

59. Petri M, Kim MY, Kalunian KC, Grossman J, Hahn BH, Sammaritano LR, Lockshin M, Merrill JT, Belmont HM, Askanase AD, McCune WJ, HearthHolmes M, Dooley MA, Von Feldt J, Friedman A, Tan M, Davis J, Cronin M, Diamond B, Mackay M, Sigler L, Fillius M, Rupel A, Licciardi F, Buyon JP; OC-SELENA Trial: Combined oral contraceptives in women with systemic lupus erythematosus. N Engl J Med 2005, 353:2550-2558.

60. Sánchez-Guerrero J, Uribe AG, Jiménez-Santana L, Mestanza-Peralta M, LaraReyes P, Seuc AH, Cravioto MD: A trial of contraceptive methods in women with systemic lupus erythematosus. N Engl J Med 2005, 353:2539-2549.

61. Sammaritano LR: Therapy insight: guidelines for selection of contraception in women with rheumatic diseases. Nat Clin Pract Rheumatol 2007, 3:273-281.

62. De-Regil LM, Fernandez-Gaxiola AC, Dowswell T, Pena-Rosas JP: Effects and safety of periconceptional folate supplementation for preventing birth defects. Cochrane Database Syst Rev 2010, (10):CD007950.

63. Janssen NM, Genta MS: The effects of immunosuppressive and antiinflammatory medications on fertility, pregnancy, and lactation. Arch Intern Med 2000, 160:610-619.

64. Østensen M, Khamashta M, Lockshin M, Parke A, Brucato A, Carp H, Doria A, Rai R, Meroni P, Cetin I, Derksen R, Branch W, Motta M, Gordon C, RuizIrastorza G, Spinillo A, Friedman D, Cimaz R, Czeizel A, Piette JC, Cervera R, Levy RA, Clementi M, De Carolis S, Petri M, Shoenfeld Y, Faden D, Valesini G, Tincani A: Anti-inflammatory and immunosuppressive drugs and reproduction. Arthritis Res Ther 2006, 8:209.

65. Vinet E, Pineau C, Gordon C, Clarke AE, Bernatsky S: Biologic therapy and pregnancy outcomes in women with rheumatic diseases. Arthritis Rheum 2009, 61:587-592.

66. Vento M, Perez AA, Ledo A, Boso V, Carey JC: Mycophenolate mofetil during pregnancy: some words of caution. Pediatrics 2008, 122:184-185

67. Minozzi S, Amato L, Vecchi S, Davoli M: Maintenance agonist treatments for opiate dependent pregnant women. Cochrane Database Syst Rev 2008, (2):CD006318.

68. Brucato A: Prevention of congenital heart block in children of SSA-positive mothers. Rheumatology (Oxford) 2008, 47 Suppl 3:iii35-iii37.

69. Costedoat-Chalumeau N, Amoura Z, Huong DL, Lechat P, Piette JC: Safety of hydroxychloroquine in pregnant patients with connective tissue diseases. Review of the literature. Autoimmun Rev 2005, 4:111-115.

70. Gayed M, Gordon C: Pregnancy and rheumatic diseases. Rheumatology (Oxford) 2007, 46:1634-1640. 
71. Tincani A, Branch W, Levy RA, Piette JC, Carp H, Rai RS, Khamashta M, Shoenfeld Y: Treatment of pregnant patients with antiphospholipid syndrome. Lupus 2003, 12:524-529.

72. Branch DW, Silver RM, Porter TF: Obstetric antiphospholipid syndrome: current uncertainties should guide our way. Lupus 2010, 19:446-452.

73. Laskin CA, Spitzer KA, Clark CA, Crowther MR, Ginsberg JS, Hawker GA, Kingdom JC, Barrett J, Gent M: Low molecular weight heparin and aspirin for recurrent pregnancy loss: results from the randomized, controlled HepASA Trial. J Rheumato/ 2009, 36:279-287.

74. Dekker G, Sibai B: Primary, secondary, and tertiary prevention of preeclampsia. Lancet 2001, 357:209-215.

75. Steegers EA, von Dadelszen P, Duvekot JJ, Pijnenborg R: Pre-eclampsia. Lancet 2010, 376:631-644.

76. Ruigómez A, García Rodríguez LA, Cattaruzzi C, Troncon MG, Agostinis L Wallander MA, Johansson S: Use of cimetidine, omeprazole, and ranitidine in pregnant women and pregnancy outcomes. Am J Epidemiol 1999 150:476-481.

77. Matok I, Gorodischer R, Koren G, Sheiner E, Wiznitzer A, Uziel E, Levy A: The safety of H(2)-blockers use during pregnancy. J Clin Pharmacol 2010, $50: 81-87$
78. Gill SK, O'Brien L, Einarson TR, Koren G: The safety of proton pump inhibitors (PPIs) in pregnancy: a meta-analysis. Am J Gastroenterol 2009, 104:1541-1545.

79. Wetzl RG: Anaesthesiological aspects of pregnancy in patients with rheumatic diseases. Lupus 2004, 13:699-702.

80. Ip S, Chung M, Raman G, Chew P, Magula N, DeVine D, Trikalinos T, Lau J: Breastfeeding and maternal and infant health outcomes in developed countries. Evid Rep Technol Assess (Full Rep) 2007, (153):1-186.

81. Ostensen M, Motta M: Therapy insight: the use of antirheumatic drugs during nursing. Nat Clin Pract Rheumatol 2007, 3:400-406.

82. Sau A, Clarke S, Bass J, Kaiser A, Marinaki A, Nelson-Piercy C: Azathioprine and breastfeeding: is it safe? BJOG 2007, 114:498-501.

83. Moretti ME, Verjee Z, Ito S, Koren G: Breast-feeding during maternal use of azathioprine. Ann Pharmacother 2006, 40:2269-2272.

doi:10.1186/ar3227

Cite this article as: Jain V, Gordon C: Managing pregnancy in inflammatory rheumatological diseases. Arthritis Research \& Therapy 2011, 13:206. 